\title{
ONU: 70 años de acciones a favor de la humanidad
}

\author{
Óscar Edgardo Velásquez Calderón' \\ Decano de la Facultad de Derecho Utec \\ edgar.velasquez@utec.edu.sv \\ Recibido: 22/11/2016 - Aceptado: 24/01/2017
}

\begin{abstract}
Resumen
El objetivo del presente artículo es exponer de forma resumida la historia de la Organización de las Naciones Unidas (ONU) y su origen a través de su Carta constitucional. Este fue preparado para dictar conferencia en la Universidad de Buenos Aires, Argentina.
\end{abstract}

El método clásico ha sido de gran auxilio en la investigación bibliográfica efectuada, lo que ha dado paso a la reflexión del tema.

La Organización de las Naciones Unidas para la Educación, la Ciencia y la Cultura (2015), figura dentro de los aportes más importantes, contribuyendo con la frase "Puesto que las guerras nacen en las mente de los hombres, es en la mente de los hombres de donde deben erigirse los baluartes de la paz". Esta aseveración permitió el análisis de los objetivos de la mencionada Carta, frente a las amenazas que, de realizarse, sufriría el planeta. El estudio hace una comparación de la época con los tiempos actuales, y concluye estableciendo que solo desde la academia es posible hacer verdaderos aportes para la paz mundial.

\section{Palabras clave}

Organización de las Naciones Unidas, carta, derechos humanos, defensores de derechos humanos, mediación internacional.

\section{Abstract}

This article focuses on summarizing the history and origin of the United Nations (UN) through its Constitution. The article was prepared for a lecture at the Universidad de Buenos Aires, Argentina.

In conducting the bibliographic research, the classical method has been of great assistance, giving way for an opportunity to reflect on the topic.

The United Nations for Education, Science and Culture (2015), stands out as one of the most important contributions of the UN, as well as its phrase "Since wars begin in the minds of men, it is in the minds of men that the defences of peace must be constructed". This assertion allowed for the analysis of the objectives contained in said Constitution and how the planet would suffer if threats towards it were to become a reality. The study establishes a comparison between past and present times; it concludes by establishing that it is only via Academia that it is possible to make true contributions for world peace.

\section{Keywords}

United Nations, constitution, human rights, human rights advocates, international mediation.

\footnotetext{
Decano de la Facultad de Derecho de la Universidad Tecnológica de El Salvador (Utec). Especialista en Derecho Constitucional y Teoría del Estado.
} 
Como preámbulo de esta intervención, es justo reflexionar sobre la buenaventura de contar con la Organización de las Naciones Unidas.

La ONU es una organización futurista; clasificada así por el objetivo con el que fue fundada. Ha sido uno de los logros más loables de todos los tiempos y una de las principales acciones humanas de las que se tiene registro sobre la tierra (ONU, 2015).

Reza la Carta de la ONU, firmada el 26 de junio de 1945, y cuya entrada en vigencia data el 24 de octubre del mismo año, según el artículo 110 de su constitución, lo siguiente:

\begin{abstract}
Nosotros los pueblos de las Naciones Unidas resueltos a preservar a las generaciones venideras del flagelo de la guerra que dos veces durante nuestra vida han infligido a la humanidad con sufrimientos indecibles, y a reafirmar la fe en los derechos fundamentales del hombre, en la dignidad y el valor de la persona humana, en la igualdad de derechos de hombres y mujeres y de las naciones grandes y pequeñas, a crear condiciones bajo las cuales puedan mantenerse la justicia y el respeto a las obligaciones emanadas de los tratados y de otras fuentes del derecho internacional, a promover el progreso social y a elevar el nivel de vida dentro de un concepto más amplio de la libertad, y con tales finalidades firmamos... (ICJ, 2015).
\end{abstract}

Lo interesante es que se inició una organización de 26 países con los mismos o similares principios, tales como el derecho a la vida, la educación, la salud, al matrimonio, a la asociación, la opinión, la libertad política y la igualdad soberana de los países. Estos a su vez dieron origen a la creación de una doctrina, logrando el nacimiento de documentos como la Declaración Universal de los Derechos Humanos y la creación de sus diferentes órganos, como el Consejo de Seguridad, que, a nuestro juicio, es el más importante sobre todos los demás, en virtud de la responsabilidad principal del mantenimiento de la paz y la seguridad internacionales (William, 1984).

Desde la perspectiva académica, esto permite formular un interrogante: si el ser humano siempre ha estado lleno de misterios, contando entre los más grandes la búsqueda de pretextos para generar una acción en contra de sus hermanos, ¿por qué nos matamos entre seres humanos?
"Puesto que las guerras nacen en las mente de los hombres, es en la mente de los hombres de donde deben erigirse los baluartes de la Paz" (Unesco, 2015).

Desde su aparición en la faz de la tierra, la humanidad ha generado guerras y conflictos para eliminarse los unos a los otros, por razones económicas, políticas, religiosas y hasta científicas.

García (2015) señala que solo en el siglo XX se contabilizaron 165 conflictos armados, con un saldo de 180 millones de seres humanos muertos. Por eso y más es considerado como el siglo más violento de la humanidad. Y como consecuencia del último conflicto mundial y de la pérdida de millones de vidas humanas en un solo evento, y de la escalada de violencia que demostró el ser humano con la detonación de dos bombas atómicas consecutivas de reacción en cadena, es que se dio origen a esta noble entidad.

Hoy celebramos 70 años de una gran organización. La primera en su género, que ha tratado por múltiples medios de detener acciones que aniquilen al ser humano. ¿Cuántas de estas acciones podríamos contabilizar en los años pasados? No obstante, como toda estructura humana tiene sus fortalezas y sus debilidades; por ejemplo: para unos, las acciones del Consejo de Seguridad obedecen a ciertas líneas políticas internacionales o de países específicos; para otros, el actuar ha sido aceptable, pero cada versión variará de acuerdo con sus respectivas percepciones.

Pero lo importante no es solo lo que se ha hecho, sino lo que se continuará haciendo por preservar y sobre todo impulsar una filosofía de unidad y de solidaridad, apoyándonos los unos a los otros en contra de múltiples intereses que rodean el desarrollo de la humanidad. Y con esto no queremos decir que estamos en contra de los diversos intereses; solo decimos que deben de estar orientados hacia las más necesitadas esferas de nuestra especie.

Por lo tanto, como académicos debemos promover, como responsabilidad imperativa de todo ser humano, la igualdad, la dignidad humana y el cumplimiento de los derechos de hombres y mujeres, de niños y niñas, la justicia y el respeto entre las naciones, así como todos aquellos derechos que bien sabemos que son universales, intransferibles e individuales (Magaña, 1997). 
Sabemos que lograr este propósito no será fácil, y que tampoco es a corto plazo, pero debemos observar las advertencias que nos ha hecho la Historia, pues en los más antiguos manuscritos de una civilización se registró la historia de un pueblo "que decidió construir una torre que llegaría al cielo para ver qué había alli; iniciaron, edificaron, pero nunca se terminó, porque sucedieron varios eventos que dieron origen a una confusión entre los constructores, y se detuvo sin lograr su objetivo... Cuentan las leyendas que aquí iniciaron los diversos idiomas del mundo" (Biblia, 1960).

La Declaración Universal de los Derechos Humanos, instrumento casi perfecto, encierra todos los principios, doctrinas y convenios que podemos lograr como miembros de un gran estado integrado, en el que la independencia de cada estado es un pilar fundamental, y donde la población, el poder y la territorialidad existen para cumplir la más imperante de todas las funciones de cada país: "satisfacer las necesidades básicas de sus miembros" (Liszczynski, 2014).

“¿Que es el hombre para que te acuerdes de él, si fue hecho poco menor que los ángeles...?" reza el Salmo del rey David para con Dios. (Biblia, 1960).

Al igual que el texto anterior, la ONU tiene destellos de una motivación divina, que los hombres han reconocido, y por eso se han organizado para buscar un bien común como finalidad.

En este contexto, hoy celebramos la filosofía del porqué en la ONU el espíritu de promover la vida humana es lo más maravilloso que nos ha pasado en años.

En nuestra experiencia, la ONU en El Salvador ha hecho mucho desde su participación en los Acuerdos de Paz, que pusieron fin a la guerra civil de los años 80 . Uno de los organismos más activos ha sido Unicef, que en los últimos años de posguerra ha trabajado denunciando la violencia que sufren las niñas, los niños y los adolescentes, quienes representan un $36 \%$ de nuestra población, así como sus niveles de pobreza, creando programas de asistencia social, por ejemplo, "¿No te indigna?"o "Unidos en acción", programas que han dado como frutos el Sistema de Protección de la Niñez y la Adolescencia, así como la Ley de Promoción y Protección de la Lactancia Materna. Hechos positivos de las políticas y acciones en apoyo a nuestra población (Lewis, 2013).

\section{Queremos terminar haciendo una invitación}

Debemos creer en la ONU. Y no solo eso: debemos apoyarle desde nuestras trincheras académicas. Es nuestro deber no perder la esperanza de que un día la raza humana se unirá y emprenderá un camino diferente, tal como se diseñó desde el principio de su existencia; con el objetivo de crear un lugar donde todos tengamos nuestras necesidades solventadas, ya sean físicas o espirituales, académicas o sentimentales. Un lugar donde el hambre y las enfermedades sean controladas. Un lugar donde cada ser humano sea reconocido por lo que es, y no por lo que pensamos que debería ser. Un lugar donde los derechos humanos tengan la solidez y la pasión por ser influencia en nuestros derechos fundamentales y garantías constitucionales, buscando un estilo de vida sin perder la cultura de cada país; y logremos dejar la carrera de construir armas, los motivos y las acciones para eliminarnos entre nosotros mismos.

\section{Referencias}

Biblia (1960). La Santa Biblia. Reina Valera, p. 714. Biblia (1960). La Santa Biblia. Reina Valera p. 15.

García, J. (31 de agosto de 2015). "Universidad Carlos III de Madrid". Obtenido de https://aplicaciones.uc3m.es/ $\mathrm{cpa} / \mathrm{cpa}$ /generarReport.do?ano=2013\&plan=165\&asig natura $=15584 \&$ idioma $=1$

ICJ (25 de agosto de 2015). Corte Internacional de Justicia. Obtenido http://www.icj-cij.org/homepage/sp/unchart.php

Lewis, G. (2013). “Situación de la niñez y la adolescencia en El Salvador. Informe anual El Salvador". El Salvador: Unicef pp. 11-14.

Liszczynski, M. (2014). Derechos fundamentales, Estados e integración. Buenos Aires: Facultad de Derecho UBA.

Magaña, Á. (1997). Derechos fundamentales y Constitución. San Salvador: Utec, pp.117-120.

ONU (26 de agosto de 2015). "Organización de Naciones Unidas". Obtenido de http://www.un.org/es/index.html

Unesco (27 de agosto de 2015). "Organización de las Naciones Unidas para la Educación, la Ciencia y la Cultura". Obtenido de http://www.unesco.org/new/es

William, T. (1984). La apertura política. Santiago de Chile: Universitaria, p. 21. 